\title{
Effects of mobile phone prolonged radiation on kidney cells; an in-vitro study
}

\author{
Golshan Mahmoudi ${ }^{1}$, Safoora Nikzad ${ }^{2 *}$, Mohammad Mehrpouyan ${ }^{3}$, Masoud Moslehi ${ }^{4}$, Milad Baradaran- \\ Ghahfarokhi $^{4,5}$, Amirreza Dashty ${ }^{6}$ \\ ${ }^{1}$ Medical Physics Department, Sabzevar University of Medical Sciences, Sabzevar, Iran \\ ${ }^{2}$ Department of Medical Physics, Faculty of Medicine, Hamadan University of Medical Sciences, Hamadan, Iran \\ ${ }^{3}$ Radiology and Radiotherapy Department, Faculty of Medicine, Sabzevar University of Medical Science, Sabzevar, Iran \\ ${ }^{4}$ Department of Medical Physics and Medical Engineering \& Students Research Committee, School of Medicine, Isfahan University of Medical \\ Sciences, Isfahan, Iran \\ ${ }^{5}$ Department of Medical Radiation Engineering, Faculty of Advanced Sciences \& Technologies, Isfahan University, Isfahan, Iran \\ ${ }^{6}$ School of Medicine, Bandar-Abbas University of Medical Sciences, Hormozgan, Iran
}

\section{A R T I C L E I N F O}

Article Type:

Original

\section{Article History:}

Received: 4 February 2018

Accepted: 10 April 2018

Published online: 6 May 2018

\section{Keywords:}

Radiofrequency radiation

Mobile phone

Kidney cell

Cell culture

\begin{abstract}
A B S T R A C T
Introduction: Mobile phones have been shown to have hazardous effects on the human renal system, reproduction and development, central nervous system and immune function.

Objectives: This study aimed to investigate whether the mobile phone prolonged radiofrequency (RF) radiation could affect healthy kidney cells in an in-vitro study.

Materials and Methods: Human kidney healthy cells in three groups were placed into three batches. The first and second groups (exposed groups) were exposed to a mobile phone simulator for 1 and $2 \mathrm{~h} / \mathrm{d}$, respectively. The irradiation was performed for 8 consecutive days. For the third group (control group), no radiation was applied to the samples and they completed the assay cycle under identical conditions. Cells' survival was evaluated using MTT [3-(4,5-dimethylthiazol-2yl)-2,5-diphenyltetrazolium bromide] assay. Statistical significance of the differences between control and exposed groups were assessed using the repeated measure ANOVA method $(P<0.05)$. Results: Results showed that radiation exposure from mobile phones simulator decreased the kidney cell survival in the exposed groups (up to 40\%). ANOVA test revealed that a significant decrease in cell survival in the exposed group compared to the control group $(P=0.014)$. No significant differences between the irradiated groups were found $(P>0.05)$.

Conclusion: Mobile phone exposure affects kidney cells survival during an in vitro condition. To study the effects of mobile phone radiation on kidney, further in vivo studies on mammalians are needed.
\end{abstract}

Implication for health policy/practice/research/medical education:

Nowadays, mobile phones are widely used not only for making calls but also for many other applications, such as banking transactions and web browsing. Histological and physiological studies have shown the hazardous effects of mobile phones on the human central nervous system, cardiovascular system, immune function, reproduction and development. It should be noted that mobile telephone radiation may be absorbed by kidney more than other internal organs because mobile phones are often carried in belts. The present study investigated that the mobile phone prolonged radiofrequency radiation could affect healthy kidney cells in an in vitro study.

Please cite this paper as: Mahmoudi G, Nikzad S, Mehrpouyan M, Moslehi M, Baradaran-Ghahfarokhi M, Dashty A. Effects of mobile phone prolonged radiation on kidney cells; an in-vitro study. J Renal Inj Prev. 2018;7(3):175-179. DOI: 10.15171/jrip.2018.42.

\section{Introduction}

The increased application of radiofrequency (RF) radiation, for domestic and industrial purposes, generated from various electrical devices such as mobile phone base transceiver stations (BTSs) and power transmission lines, proves that RF plays a critical role in human daily life
(1). In this regard, the emergence of telecommunication services using electromagnetic field (EMF) principles greatly enhance the ability of individuals and groups to communicate with each other $(2,3)$.

Nowadays, mobile phones are used not only for making and receiving calls but also for many other applications, 
such as banking transactions and web browsing. According to International Telecommunication Union (ITU), about 4.6 billion mobile phones subscribers in the world was estimated in 2009, and it was expected to reach 8 billion by 2015 , which represent one of the fast growing environmental influences (1).

In recent years many histological and physiological studies have been performed in the evaluation of the hazardous effects of EMF on human health regarding cancer, renal system, reproduction and development, central nervous system and immune function (4-10).

The emitted RF radiation from mobile phones have been shown to have many effects upon the sperm motility and morphology $(11,12)$, immune functions (10), mammalian brain (3), and neurological pathologies syndrome (13). However, many potential harmful effects of cell phone exposure remain controversial $(10,12)$. Hinrikus et al have shown that the EEG beta rhythms of human brain were significantly increased by exposure to $450 \mathrm{MHz} R F$ radiation (14). Lai et al studied the effects of microwave radiation on cholinergic systems of rat brain $(7,15,16)$. They showed that a dose-response relationship for each brain region with respect to different microwave power densities was existed $(7,15,16)$. Nittby et al investigated that RF radiation affected the mammalian bloodbrain barrier permeability 7 days after exposure to the radiation from a $900 \mathrm{MHz}$ mobile phone radiation (17). Moreover, other experimental studies in mammals have shown that exposure to mobile phone radiation led to considerable testicular germ cell morphological changes and apoptosis (18-20). Lu et al found that air conditioners, which generate significant amounts of RF radiation, are associated with low semen quality (21). In addition, it is now generally accepted that this kind of radiation can activate DNA to synthesize proteins (22). Furthermore, recent reports have revealed that long-term exposure to EMF decreases thyroid tri-iodothyronine-thyroxin (T3) levels and stimulating hormone $(9,23)$.

The mobile telephone RF radiation may be absorbed by pelvic organs, especially the kidney, more than other internal organs because mobile phones are often carried in belts. According to the best of our knowledge, no study on the effects of cell phone prolonged RF radiation on the kidney cells has been published.

\section{Objectives}

The aim of this study was to investigate whether the mobile phone prolonged RF radiation could affect healthy kidney cells in an in-vitro study.

\section{Materials and Methods}

\section{Cell culture and mobile phone radiation}

Human kidney healthy cells, provided from Isfahan University of Medical Science Laboratory (Isfahan, Iran) were cultured in $25 \mathrm{~mL}$ culture flasks in Dulbecco's modified Eagle's medium (DMEM Gibco Laboratories, Cergy Pontoise, France) including 10\% fetal bovine serum (FBS Gibco Laboratories, Cergy Pontoise, France), $100 \mathrm{U} / \mathrm{mL}$ penicillin, $2 \mathrm{mM}$ glutamine, and $100 \mathrm{mg} /$ $\mathrm{mL}$ streptomycin (Gibco Laboratories, Cergy Pontoise, France). A humidified cell incubator, with $5 \% \mathrm{CO}_{2}$ atmosphere and $95 \%$ air, was used for the cells growth at $37^{\circ} \mathrm{C}$.

Before the experiment, cells were trypsined by trypsineEDTA (Gibco, Invitrogen, Carlsbad, CA, USA) and plated at a density of $10^{4}$ cells/well in 96-well culture plates.

The cells were divided into three groups and were placed into three batches. The first and second groups (exposed groups) were exposed to a mobile phone simulator for 1 and $2 \mathrm{~h} / \mathrm{d}$, respectively, for 8 days. The simulator produced $900 \mathrm{MHz}$ RF radiation, to represent the exposure of GSM. The distance between the simulator antenna and each specimen was kept at $2.5 \mathrm{~cm}$. The cells in the third group (control group) were completed the assay cycle with no radiation.

Cells' survival was evaluated using MTT [3-(4,5-dimethylthiazol-2-yl)-2,5-diphenyltetrazolium bromide] assay at different days during and post-irradiation period.

\section{Mobile phone simulator}

A mobile phone simulator (designed and produced at the Medical Physics Department, School of Medicine, Isfahan University of Medical Sciences) was used for RF irradiation. In this experiment, similar to mobile phone, the frequency of $900 \mathrm{MHz}$ radiation (a wavelength of about $33.4 \mathrm{~cm}$ ) was used. The simulator power was adjusted to $1.0 \mathrm{~W}$ for the exposure.

\section{MTT assay}

The MTT assay involves the conversion of the MTT in the form of water-soluble to an insoluble formazan. The MTTs was dissolved in sterile phosphate-buffered saline (PBS) at $5 \mathrm{mg} / \mathrm{mL}$, the solution was filtered and stored in dark condition at $4^{\circ} \mathrm{C}$ for less than 3 weeks.

Five wells of a 96-well plate were used for every experimental condition. The medium was renewed, without making any damage to the adhesive cells, every three days to avoid possible medium product inaccuracy. For the MTT assay, according to our basic protocol, the solution with proper concentration $(10 \mu \mathrm{L}$ MTT solution in each $100 \mu \mathrm{L}$ media) was added to each well and the plates were then incubated at $37^{\circ} \mathrm{C}$ for 4 hours. Following the incubation, the remaining MTT solution was removed and $100 \lambda$ of dimethyl sulphoxide (DMSO) was added to each well to dissolve the formazan crystals. In order to ensure adequate solubility, the plates containing the cells were shaken for 5 minutes using a plate shaker. Absorbance readings of each well were performed at 570 $\mathrm{nm}$ (single wavelength) using an ELISA reader (Stat Fax 2100, Awareness Technology Inc., USA). It should be noted that the amount of the formed purple formazan crystals is directly correlated with the number of viable cells. The study was repeated for three independent trials to avoid the intrinsic variability of the assay used. 


\section{Ethical issues}

The research followed the tenets of the Declaration of Helsinki, and the study was approved by the ethical committee of Sabzevar University of Medical Sciences, Iran (grant \#1394-43).

\section{Statistical analysis}

Mean values and standard deviations of the cell's survival were calculated. Statistical significance of the differences, between control and exposed groups, was evaluated using ANOVA method in SPSS version 16.0 (Chicago, IL, USA). A significant level of 0.05 was considered to the tests.

\section{Results}

Results showed that radiation exposure from mobile phones simulator decreased the kidney cell survival in the exposed groups (Table 1). Table 1 gives the variance analyses of the effects of day, group and the interaction between these two parameters. Using the ANOVA test, a significant decrease in cell survival in the exposed group compared to the third group (control one) was seen $(P=$ 0.014) (Figure 1). In other words, the kidney cell survival in the assay was affected by exposure from $900 \mathrm{MHz}$ mobile phone simulator, following 1 to $2 \mathrm{~h} / \mathrm{d}$ irradiation for 8 consecutive days. No significant differences were investigated between the irradiated groups $(P>0.05)$. It means that a significant difference between 1 and $2 \mathrm{~h} / \mathrm{d}$ irradiated groups was detected. Therefore, although the level of cell death in various days was different (the effect of day) in all groups these differences were the same.

\section{Discussion}

Currently, the use of mobile phones has become one of the fastest growing technological developments worldwide (12). Due to close proximity of the mobile phone antenna to the pelvic organs, the emitted radiation from such phones has raised concerns about the biological effects of RF radiation on the kidney (24). The 900-MHz mobile phones are widely used in Iran and in many other countries and they usually carried in belts close to kidney. According to our knowledge, direct biological effects of kidney due to exposure to mobile phone RF radiation have not been studied extensively. This study aimed to investigate the biological effects of mobile phone prolonged RF radiation on kidney cell.

In this work, kidney cells were irradiated to RF radiation of a mobile phone simulator for 8 days and 1 to 2 hour/day. It should be noted that to study the hazardous effects, the

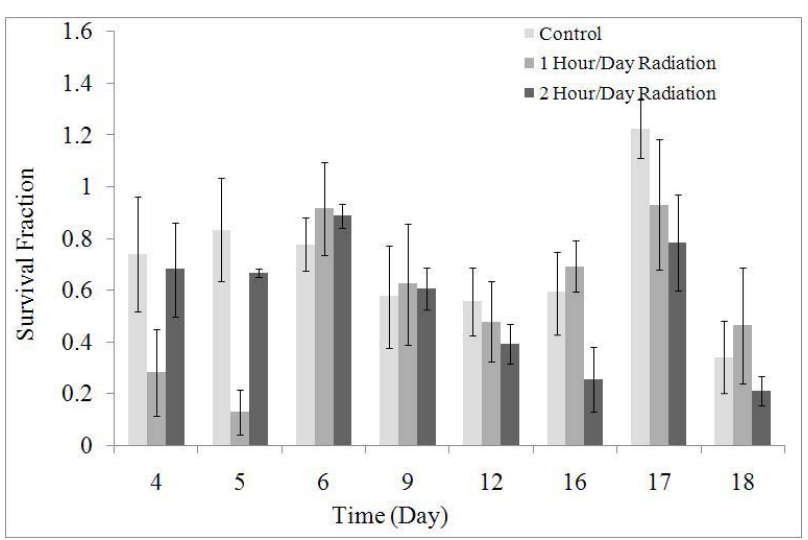

Figure 1. A comparison of average \pm SD kidney cell survival among control and the mobile phone exposed groups in different days.

duration period for mobile phone use and its frequency are main factors, but the exact duration varies from individual to individual $(10,12)$. Therefore, the estimated average time of mobile phone use was considered for RF radiation.

Results of our study showed that kidney cell survival decreased due to mobile phone RF radiation $(P=0.014)$. However, differences were not significant between the irradiated groups $(P>0.05)$. In other words, there was not a significant difference between 1 and $2 \mathrm{~h} / \mathrm{d}$ irradiated groups.

Recently, studies on kidney reported that melatonin plays a regulatory role in renal system and affects urine output $(8,25)$. Moreover, localizations of specific melatonin receptors have been found in renal tissue (26). This finding is highly suggestive of a direct critical role for melatonin in the renal function. It should be noted that specific receptors of melatonin are found in renal tissue and they have strong biological inference which indicates the effects on cellular actions throughout intracellular signaling and transduction of the membrane (24).

Oktem et al have reported that exposure to mobile phone $\mathrm{RF}$ radiation imposed a significant effect on rat kidney (24). However, their results showed that melatonin, as an efficient free radical scavenger, may exhibit a protective effect on mobile phone-induced renal impairment in rats (24). Moreover, it has been reported that RF radiation also resulted in the expansion of free radicals and decrease in the levels of serum melatonin (27).

Al-Glaib et al reported that the exposed mice kidney to electromagnetic radiation from a mobile phone resulted

Table 1. Variance analyses of the studied groups of kidney cells

\begin{tabular}{llllll}
\hline Source & Type III Sum of Squares & df & Mean Square & F & \multicolumn{1}{c}{ P } \\
\hline Day & 2.420 & 1.000 & 2.420 & 0.014 \\
Group & 0.315 & 2.000 & 0.158 & 1.423 & 0.312 \\
Day * Group & 1.631 & 2.000 & 0.816 & 3.897 \\
Error (day) & 1.256 & 6.000 & 0.209 & \\
Error (group) & 0.664 & 6.000 & 0.111 & \\
\hline
\end{tabular}


in more mononuclear leukocyte infiltration between the renal tubules, compared to the sham exposed group (28). In addition, they have stated that following the radiation, some glomeruli were atrophied and some kidney tubules were vacuolated (28).

The results of this study were obtained by using a commercial $1.0 \mathrm{~W}$ at $900 \mathrm{MHz}$ mobile phone simulator to reproduce the reality of the human exposition. Due to limitations and difficulties associated with in vivo studies, in this work an in vitro experiment was performed to investigate the effects of exposure to the cell phone on the kidney cells. Nevertheless, in vivo studies, on either animals or human beings, may provide more convincing evidence of the EMF effects.

\section{Conclusion}

In this work, the biological effects of mobile phone prolonged RF radiation on kidney cell were studied. Results showed that mobile phone exposure affects kidney cells survival during an in vitro condition. To study the effects of mobile phone radiation on kidney, further in vivo studies on mammalians are needed. However, the evaluation of the possible effects of mobile phones radiation on the living organism is a complex process that needs the combined contributions of many scientific regulations.

\section{Limitations of the study}

More accurate follow up studies on mammalian kidney are needed for the evaluation of the effects of the mobile phone. The results here should be more evaluated in larger series, employing repeated in vivo exposure-dose related effect design and providing a detailed assessment of the radiation dose produced by the phones.

\section{Acknowledgments}

The authors would like to thank Dr Yousof Gheisary and Dr Shiva Moein from genetic department, Isfahan University of Medical Sciences, Isfahan, Iran for their critical comments and technical advice.

\section{Authors' contribution}

GM was the principal investigators of the study. GM, $\mathrm{SN}$ and MBGh participated in preparing the concept and design. MM and $\mathrm{AD}$ revisited the manuscript and critically evaluated the intellectual contents. All authors participated in preparing the final draft of the manuscript, revisited the manuscript and critically evaluated the intellectual contents. All authors have read and approved the content of the manuscript and confirmed the accuracy or integrity of any part of the work.

\section{Conflicts of interest}

The authors report no conflicts of interest. The authors alone are responsible for the content and writing of this paper.
Ethical considerations

Ethical issues (including plagiarism, data fabrication, double publication) have been completely observed by the authors.

\section{Funding/Support}

The study was supported by a grant from Sabzevar University of Medical Sciences (grant \#1394-43).

\section{References}

1. Hamadoun T. Strong global mobile cellular growth across all regions. International Telecommunication Union Mobile World Congress; Bercelona 2010.

2. Ammari M, Brillaud E, Gamez C, Lecomte A, Sakly M, Abdelmelek H, et al. Effect of a chronic GSM $900 \mathrm{MHz}$ exposure on glia in the rat brain. Biomed Pharmacother. 2008;62:273-81.

3. de Tommaso M, Rossi P, Falsaperla R, Francesco Vde V, Santoro R, Federici A. Mobile phones exposure induces changes of contingent negative variation in humans. Neurosci Lett. 2009;464:79-83. doi:10.1016/j. neulet.2009.08.045

4. Chang KB, Huang AT, Joines WT, Kramer RS. The effect of microwave radiation $(1.0 \mathrm{GHz})$ on the blood-brain barrier in dogs. Radio Sci. 1982;17:165-8. doi: 10.1029/ RS017i05Sp0165S

5. Khaki AA, Tubbs RS, Shoja MM, Rad JS, Khaki A, Farahani $\mathrm{RM}$, et al. The effects of an electromagnetic field on the boundary tissue of the seminiferous tubules of the rat: A light and transmission electron microscope study. Folia Morphol. 2006;65:188-94.

6. Khaki AA, Zarrintan S, Khaki A, Zahedi A. The effects of electromagnetic field on the microstructure of seminal vesicles in rat: a light and transmission electron microscope study. Pak J Biol Sci. 2008;11:692-701. doi: 10.3923/ pjbs.2008.692.701

7. Lai H, Horita A, Guy AW. Acute low-level microwave exposure and central cholinergic activity: studies on irradiation parameters. Bioelectromagnetics. 1988;9:35562. doi: 10.1002/bem.2250090405

8. Ozguner F, Ozcankaya R, Delibas N, Boz F. Melatonin effects adrenocortical aldosterone secretion and plasma electrolyte levels. Turk J Med Sci. 1995;27:201-3.

9. Rajkovic V, Matavulj M, Gledic D, Lazetic B. Evaluation of rat thyroid gland morphophysiological status after three months exposure to $50 \mathrm{~Hz}$ electromagnetic field. Tissue Cell. 2003;35:223-31. doi: 10.1016/S0040-8166(03)00029-6

10. Repacholi $\mathrm{MH}$. Health risks from the use of mobile phones. Toxicol Lett. 2001;120:323-31. doi:10.1016/S03784274(01)00285-5

11. Agarwal A, Desai NR, Makker K, Varghese A, Mouradi R, Sabanegh E, et al. Effects of radiofrequency electromagnetic waves (RF-EMW) from cellular phones on human ejaculated semen: an in vitro pilot study. Fertil Steril. 2009;92:1318-25. doi: 10.1016/j.fertnstert.2008.08.022

12. Valberg PA, van Deventer TE, Repacholi MH. Workgroup report: base stations and wireless networks-radiofrequency (RF) exposures and health consequences. Environ Health Perspect. 2007;115:416-24. doi: 10.1289/ehp.9633

13. Leszczynski D, Joenvaara S, Reivinen J, Kuokka R. Nonthermal activation of the hsp27/p38MAPK stress pathway 
by mobile phone radiation in human endothelial cells: molecular mechanism for cancer- and blood-brain barrierrelated effects. Differentiation. 2002;70:120-9. doi:10.1046/ j.1432-0436.2002.700207.x

14. Hinrikus H, Bachmann M, Lass J, Karai D, Tuulik V. Effect of low frequency modulated microwave exposure on human EEG: individual sensitivity. Bioelectromagnetics. 2008;29:527-38. doi: 10.1002/bem.20415

15. Lai H, Carino MA, Horita A, Guy AW. Low-level microwave irradiation and central cholinergic activity: a dose-response study. Bioelectromagnetics. 1989;10:203-8. 10.1002/ bem. 2250100209

16. Lai H, Horita A, Chou CK, Guy AW. Low-level microwave irradiations affect central cholinergic activity in the rat. J Neurochem. 1987;48:40-5. doi: 10.1111/j.1471-4159.1987. tb13124.x

17. Nittby H, Brun A, Eberhardt J, Malmgren L, Persson BR, Salford LG. Increased blood-brain barrier permeability in mammalian brain 7 days after exposure to the radiation from a GSM-900 mobile phone. Pathophysiology. 2009;16:103-12. doi: 10.1016/j.pathophys.2009.01.001

18. Lee JS, Ahn SS, Jung KC, Kim YW, Lee SK. Effects of 60 $\mathrm{Hz}$ electromagnetic field exposure on testicular germ cell apoptosis in mice. Asian J Androl. 2004;6:29-34.

19. Hong R, Liu Y, Yu YM, Hu K, Weng EQ. Effects of extremely low frequency electromagnetic fields on male reproduction in mice. Zhonghua Lao Dong Wei Sheng Zhi Ye Bing Za Zhi. 2003;21:342-5.

20. Hong R, Zhang Y, Liu Y, Weng EQ. Effects of extremely low frequency electromagnetic fields on DNA of testicular cells and sperm chromatin structure in mice. Zhonghua Lao Dong Wei Sheng Zhi Ye Bing Za Zhi. 2005;23:414-7.
21. Lu M, Wu J, Yang Q, Zhou W, Gao E. The effect of airconditioner exposure on semen quality. Reprod Contracept. 2004;24:279-84.

22. Lin $H$, Blank $M$, Goodman R. A magnetic fieldresponsive domain in the human HSP70 promoter. J Cell Biochem. 1999;75:170-6. doi: 10.1002/(SICI)10974644(19991001)75:1<170::AID-JCB 17>3.0.CO;2-5

23. Koyu A, Cesur G, Ozguner F, Akdogan M, Mollaoglu H, Ozen S. Effects of $900 \mathrm{MHz}$ electromagnetic field on TSH and thyroid hormones in rats. Toxicol Lett. 2005;157:25762. doi:10.1016/j.toxlet.2005.03.006

24. Oktem F, Ozguner F, Mollaoglu H, Koyu A, Uz E. Oxidative damage in the kidney induced by $900-\mathrm{MHz}$-emitted mobile phone: protection by melatonin. Arch Med Res. 2005;36(4):350-5. doi: 10.1016/j.arcmed. 2005.03.021

25. Csaba G, Bokay J. The effect of melatonin and corpus pineale extract on serum electrolytes in the rat. Acta biologica Academiae Scientiarum Hungaricae. 1977;28:143-4.

26. Pang SF, Dubocovich ML, Brown GM. Melatonin receptors in peripheral tissues: a new area of melatonin research. Biological signals. 1993;2:177-80. doi: 10.1159/000109490

27. Reiter RJ, Tan DX, Poeggeler B, Kavet R. Inconsistent suppression of nocturnal pineal melatonin synthesis and serum melatonin levels in rats exposed to pulsed DC magnetic fields. Bioelectromagnetics. 1998;19:318-29. doi: $\quad$ 10.1002/(SICI)1521-186X(1998)19:5<318::AIDBEM6>3.0.CO;2-4

28. Al-Glaib B, Al-Dardfi M, Al-Tuhami A, Elgenaidi A, Dkhil M. A technical report on the effect of electromagnetic radiation from a mobile phone on mice organs. Libyan J Med. 2008;3:8-9.

Copyright (c) 2018 The Author(s); Published by Nickan Research Institute. This is an open-access article distributed under the terms of the Creative Commons Attribution License (http://creativecommons.org/licenses/by/4.0), which permits unrestricted use, distribution, and reproduction in any medium, provided the original work is properly cited. 